nía Freud en su Metapsicología (1915) es parte del funcionamiento mental enraizado en la biología y en la cultura, de allí que teorías metapsicológicas como la de André Green (1970) vengan ganando espacio en el campo psicoanalítico y den cuenta de nuevos enfoques en el quehacer clínico. Tampoco se encuentran referencias de otros ensayos acerca del afecto, esta vez como fuerza integradora importante, tal como ha sido tratada por Robert Emde (1976), conceptos que han dado paso a estudios de carácter social como aquellos sobre la resilencia (Stefan Vanistendael, Lovaina, Bélgica, 1979).

La propuesta del compilador, Alejandro Ávila, es la de seguir ampliando los temas tratados. Esperamos fervientemente ver llenado este vacío.

Alicia Atocha

Cooper, C. \& Robertson, I. (1999)

\title{
International Review of Industrial and Organizational Psychology
}

Vol. 14, New York: Jhon Wiley \& Sons. Xi + 422 pp.

Es el decimocuarto volumen de la International Review of Industrial and Organizational Psychology. Las revisiones son efectuadas por autores de Australia, Alemania, Holanda, España, Inglaterra y Estados Unidos. Los tópicos incluidos son de interés permanente para los psicólogos I/O, al considerar los métodos de selección de personal, seguridad laboral, control y bienestar en el trabajo, así como temas de investigación más reciente, como son los sistemas de retroinformación multifuente y el amedrentamiento en el trabajo. Los editores han otorgado en este volumen una particular atención al desempeño laboral, con capítulos sobre desempeño laboral, ciudadanía organizacional, conflicto y desempeño en grupos u organizaciones.

Los capítulos contienen los más recientes aportes sobre los temas considerados, presentando de manera sistemática los resultados de investigaciones empíricas, así como avances teóricos y conceptuales. Destaca el interés de los autores por identificar los logros, limitaciones y las necesidades de investigación en cada tópico. La mayoría de los autores son investigadores del tema que tratan, de manera que incluyen sus aportes en cada revisión. A continuación bosquejamos el contenido de los capítulos.

"Métodos de selección de personal" procede a resumir investigaciones sobre la validez de los métodos de selección de personal, tradicionales y los de más reciente creación, como es el caso de la evaluación en base a video y la metodología de la realidad virtual. Proporciona información sobre el análisis de las actitu- 


\section{Reseñas}

des y reacciones de los postulantes frente a la evaluación, así como avances metodológicos sobre el tema.

"Seguridad del sistema: Un campo emergente para la psicología I/O", inicialmente considera la evolución de las orientaciones sobre el estudio de los accidentes en los ámbitos laborales, hasta llegar a la tendencia más reciente la cual, desde una perspectiva sistémica e incluyendo las relaciones interorganizacionales, se propone una mejor ayuda a las organizaciones complejas y con un alto riesgo de accidentes. Los autores precisan algunos aspectos en los que la psicología I/O necesitaría desarrollar e investigar para contribuir en la seguridad laboral desde una perspectiva sistémica.

"Control laboral y bienestar del empleado: Revisión de una década" considera específicamente las investigaciones efectuadas en la última década sobre el modelo demanda-control propuesto por Karasek (1973), según el cual un alto nivel de control laboral por parte de los trabajadores puede constituir un recurso para afrontar grandes demandas laborales, sin consecuencias psicológicas adversas. La información analizada proporciona un apoyo débil al modelo, pero los autores justifican mayor investigación en el futuro, con una mejor conceptualización de las variables y el uso de diseños de investigación longitudinal.

"Sistemas de retroinformación multifuente". Una perspectiva de investigación aborda uno de los más recientes temas de investigación en los ámbitos laborales: los sistemas de retroinformación multifuente, a veces denominados sistemas de "feedback de 360 grados", a través de los cuales se proporciona información al trabajador sobre su desempeño, desde la perspectiva del jefe, colegas, subordinados, clientes internos y externos, además de la autoevaluación. Se revisan investigaciones vinculadas con las propiedades psicométricas de las distintas fuentes de retroinformación. Luego se analizan los efectos de la retroinformación sobre las actitudes y rendimiento de los trabajadores involucrados. Finalmente, se incluyen algunas teorías para así orientar la investigación futura.

"Amedrentamiento en el trabajo" revisa otra de las recientes áreas de investigación en el comportamiento organizacional: el amedrentamiento, abuso, maltrato o acoso, que se presenta en las organizaciones. Inicialmente, se abordan aspectos conceptuales, identificación y efectos del amedrentamiento. Con fines explicativos se recurre a las teorías de la agresión y atribución, así como a la naturaleza del estrés. Complementan la revisión teorías vinculadas con la prevención y rehabilitación. Se indaga en las peculiaridades metodológicas de la investigación sobre dicho tema.

"Desempeño laboral: Una perspectiva de regulación múltiple" utiliza cinco teorías sobre autorregulación como un marco conceptual para proceder con la revisión. Dichas teorías están relacionadas con la regulación de la acción, energía, emoción, vitalidad y autoestima. El autor considera diversos factores que, desde un nivel individual, grupal y organizacional, influyen en el desempeño de los tra-

\section{4}


bajadores. Este capítulo es el más extenso del libro, por su amplitud de enfoque y la cantidad de información revisada, la cual incluye cerca de 600 referencias. Otro aspecto que destaca es el énfasis en los enfoques teóricos, constituyendo así una diferencia favorable frente a otras revisiones pasadas.

"Un nuevo tipo de desempeño para la psicología industrial y organizacional: Recientes contribuciones al estudio de la conducta de ciudadanía organizacional", realiza una revisión histórica del concepto de "conducta de ciudadanía organizacional" (CCB), el cual está vinculado a las acciones de los trabajadores que van más allá de su rol laboral, y que de manera voluntaria lo efectúan para contribuir con un clima psicológico favorable a la ejecución de las tareas. Se analizan investigaciones relacionadas con las consecuencias de la CCB en el plano individual, grupal y organizacional. Además, indaga sus vínculos con el liderazgo y contrato psicológico. Finalmente, se sugieren áreas prioritarias que requieren ser investigadas con más detenimiento.

"Conflicto y desempeño en grupos y organizaciones" indica que se ha investigado mucho sobre el conflicto como proceso y sus consecuencias; pero, faltaba un conocimiento sistemático sobre el conflicto y su relación con el desempeño en las organizaciones laborales. Este capítulo está orientado a suplir dicha carencia. Se tiene en cuenta el conflicto de recursos y el vinculado a la información, luego del cual considera la intervención de una tercera parte para solucionar conflictos. El autor demuestra la utilidad de tener en cuenta los efectos del conflicto a corto y largo plazo, sobre el desempeño contextual y desempeño de tarea.

Los autores de los diversos capítulos, si bien incluyen información actualizada, difieren en los años que consideran para proceder con las revisiones, así, por ejemplo, para un capítulo se analiza la última década, y para otro cinco años. Pensamos, que los editores debieron señalar un tiempo máximo como referencia, puesto que al dejar en libertad dicho criterio, los autores al revisar muchos años pueden incluir información que en otras revisiones ya se consideró.

Con excepción de los capítulos sobre selección de personal y desempeño laboral, los autores tienden a otorgar relevancia a los aportes de la psicología norteamericana, en desmedro de los trabajos de la psicología europea, a pesar de que ésta ha mostrado contribuciones útiles en la especialidad (Pieter, et al., 1998, Handbook of work and organizational psychology). Si bien los editores convocaron a autores de diversos países para conseguir una revisión internacional, por razones de preferencias de dichos autores, no se ha logrado del todo lo deseado. Además, la claridad expositiva es variada según los capítulos; algunos son muy didácticos, pero no faltan otros que requieren esfuerzo para su comprensión.

Para concluir, podemos afirmar que este texto, a pesar de las observaciones señaladas, constituye una excelente ayuda para los psicólogos vinculados al área de psicología industrial y organizacional, para permitirles estar actualizados con los avances de la materia, y, de igual manera, es una fuente valiosa para los estu- 
diantes que estén interesados en profundizar el análisis en determinadas áreas de la especialidad o realizar investigaciones sobre el comportamiento organizacional.

Arturo Solf

Ortiz, Pedro (1998)

\section{El nivel consciente de la memoria: una hipótesis de trabajo}

Lima: Universidad de Lima. 123 pp.

Es frecuente encontrar el siguiente concepto: "La memoria es parte de la actividad cognitiva y ocurre únicamente en los procesos de conocimientos y destrezas". Pocos neurólogos o psicólogos se hacen problemas con tal concepción pero el profesor Pedro Ortiz plantea reinterpretaciones de las observaciones clínicas y experimentales sobre el tema.

El capítulo que sigue a la introducción objeta los modelos tradicionales en los que hay descripciones de hechos reales que no van más allá de la realidad observada, descrita o manipulada; hay explicaciones de hechos comprobados que no tienen importancia científica ya que no se enmarcan dentro de un modelo conceptual que dé cuenta del desarrollo esencial de los hechos; existen explicaciones que se basan en datos incompletos; se observa una sobreestimación de términos o conceptos.

Como alusión a un modelo genérico se toma el de Perani, que es una síntesis de la concepción actual de la memoria. Se trata de un marco conceptual insuficiente, criticable por su carácter descriptivo, por basarse en el sentido común y por la variabilidad de categorías. Cito a Ortiz: "La cuestión es que en la clasificación de las memorias no se ha tomado en cuenta la verdadera naturaleza de contenidos y procesos y ambos han sido considerados como dos clases separadas de memoria" (p. 21).

Luego se critica la idea mecanicista del multialmacén, ya que si se da por hecho que la memoria es un conjunto de compartimientos o módulos sucesivos o en paralelo dentro del esquema cognitivo, se necesitaría ubicar el engrama en algún lugar del cerebro, afán que nunca ha tenido éxito. Finalmente, critica la idea de niveles de procesamiento, ya que mantiene el concepto idealista de la memoria como un constructo o como un componente abstracto de la cognición. La cuarta crítica es a su restricción del concepto de memoria a la actividad cognitiva y la última objeción es al asunto de la primacía de oposiciones.

En el siguiente capítulo se presenta un marco conceptual con dos premisas fundamentales: que los sistemas vivos son sistemas de información y los niveles de organización de la persona son sistemas de memoria. El concepto de información que Ortiz maneja es una forma de reflexión de la materia que es la base de todos los niveles de organización, desde la célula hasta lo social, y es requisito esencial 